\title{
Investigation On The Possibility Of Using Water-Based Polyurethane Acrylates In The Production Process Of Fiberglass Reinforced Composite Materials
}

\author{
Andrey Matev ${ }^{1}$, Kiril Dimitrov ${ }^{2}$, Torsten Döhler ${ }^{2}$, Petar Velev $^{1}$, Michael \\ Herzog $^{2}$ \\ ${ }^{1}$ University of Chemical Technology and Metallurgy (UCTM), Sofia 1000, Bulgaria \\ ${ }^{2}$ Technische Hochschule Wildau TH-Wildau, Wildau 15745, Germany
}

\begin{abstract}
Water-borne polyurethane-acrylate (WPUA) oligomer was prepared via in-situ and anionic selfemulsifying method from Hexamethylene diisocyanate, polyether polyol, dimethylolbutanoic acid, and capped with 2-Hydroxyethyl methacrylate. Subsequently, UV-curable WPUA oligomers were used to prepare glass fibre reinforced composite materials with 2-hydroxyethyl acrylate as reactive diluent and Irgacure 500 as a photoinitiator and glass fabric for reinforcing. The possibility of obtaining glass fiber reinforced composite materials on the basic of water-borne polyurethane-acrylates is of great interest to researchers due to the expected properties. For additional research, fiberglass reinforced UV-curable composites were compared, with two water-borne polyurethane acrylate commercial products and Irgacure 500 as photoinitiator. For UVcuring and reinforcing of all composites a black mercury lamp as a UV-light source and glass-fabric with different weight $-81 \mathrm{~g} / \mathrm{m}^{2}, 163 \mathrm{~g} / \mathrm{m}^{2}, 660 \mathrm{~g} / \mathrm{m}^{2}$ was used. The infrared spectrums of the obtained glass fibre reinforced composite were determined. Mechanical properties (Tensile Strength, Young's modulus) and thermal properties by Differential scanning calorimetry of UV-cured composites also investigated. The oligomers were selected as a material for application in fibreglass composite manufacturing. The results indicate that the used matrixes are suitable for quick preparing of fibreglass composites and that they could be useful for the implementation of repair strategies of similar composite materials.
\end{abstract}

Keywords: Fiberglass composites, UV-curable, water-borne polyurethane-oligomer

\section{Introduction}

Composite materials emerged in the middle of the 20th century as a promising class of engineering materials providing new prospects for modern technology. Generally speaking, any material consisting of two or more components with different properties and distinct boundaries between the components can form a two phases system and could considered as a composite material. Moreover, the idea of combining several components to produce a material with properties that are not attainable with the individual components has been used by man for thousands of years. Such materials offer advantages over conventional isotropic structural materials such as steel, aluminum or plastic. These advantages include high strength, low weight, good fatigue behavior, corrosion resistance and also desirable optical properties and appearance. Mainly the composites consists of two phases: the first phase is called matrix and the second is the phase of fillers or fibers that are immersed in the matrix and is known as discontinuous phase. The excellent properties of composites are achieved by the favorable characteristics of the two constituents namely matrix and filler/fiber [1].

Polyurethanes (PUs) are used in extensive fields of commercial applications [2]. They are unique polymeric materials with a wide range of physical and chemical properties [3]. Polyurethanes are usually used as adhesives, coatings, foams, and different kinds of elastomers, as well as matrix for polymeric composites [4].

Recently, water-borne polyurethane-acrylate (WPUA) has been developed largely because of its solvent-free, excellent mechanical properties, fire resistance, low toxicity and lack of environmental hazards [5]. The water-borne polyurethane-acrylates cross-linked by ultraviolet (UV)-curing technology, have gained an increased interest due to their advantages, such as high curing speed, cost efficiency, high chemical stability and low-VOC [6]. Light - induced polymerization of monomers or oligomers, also called UV-radiation curing, has become a well-accepted technology which has found a large variety of industrial applications [7]. UV- radiation curing has been used successfully to produce polymer composites [8]. This is the process of film formation from a reactive liquid into a solid by radiation in the ultraviolet energy region rather than by heat. UV-cured coatings form networks induced by photons and are one of the most important classes of coatings [9].

The most extensively used UV-curable resins are based on acrylates, which exhibit high reactivity, i.e. short reaction times down to the order of magnitude of fractions of a second, and offer a large choice of monomers and telechelic oligomers with functional end groups. Acrylate-based resin systems typically consist of three basic components namely, an acrylate functionalized oligomer, which forms the polymer network, 
acrylate monomers (small molecules containing one or more vinyl groups) and a photoinitiator, which generates free radicals on UV exposure [10]. Furthermore, the high reactivity of acrylates leads to a fast photo polymerization process and saves time in industrial processes [11].

In the UV-curing technology of water-borne polyurethanes acrylates oligomers are usually used with reactive diluents. The first function is to dilute the oligomer and reduce its viscosity and the second function is the inclusion of the diluent in the reactive process of the oligomer with a view of making a polymer with a desired property for some specific purpose [12].

Laminated plastics are produced in large volumes by the industries in the form of semi-finished components, laminated sheets, tubes, rods and a multitude of products like wood, cellulose or glass fabric bonded together by synthetic resins [13].

The aim of the study is to investigate the possibility of using polyurethane acrylates in the production process of glass fiber reinforced composites and characterization of their properties and subsequent usage. Such kind of composite materials can be useful for carrying out quick repairs of similar composite materials (used in wind turbines, small planes and boats). The possibility of obtaining glass fiber reinforced composite materials on the basis of water- borne polyurethane- acrylates is of great interest to researchers due to the expected application. It is rarely to find scientific research literature, concerning composite materials reinforced with glass fibers and water-borne polyurethane-acrylates as a matrix.

\section{Materials}

\section{Experimental}

The materials which were used in the present study are:

- WPUA - Water-borne polyurethane-acrylate oligomer, which was prepared via in-situ and anionic selfemulsifying method. [14].

- WPUA 2317 under the trade name Bayhydrol ${ }^{\circledR}$ 2317-Urethane acrylate dispersion, which was delivered by Covestro, Germany.

- WPUA 2689 under the trade name Bayhydrol ${ }^{\circledR}$ 2689-Anionic UV-curable polyurethane dispersion delivered by Covestro, Germany.

- Irgacure 500 - is a liquid mixture of two photoinitiators supplied by BASF Schweiz AG, Germany.

- Glass fabrics (silane coated) with the weight of $81 \mathrm{~g} / \mathrm{m}^{2}, 163 \mathrm{~g} / \mathrm{m}^{2}$ and $660 \mathrm{~g} / \mathrm{m}^{2}$, delivered by XP- Textiles $\mathrm{GmbH}$.

The current content of the obtained glass-fiber composites and their fiber volume is presented in Table 1 and a general overview is shown on Pic.1.

\begin{tabular}{|c|c|c|c|c|c|c|c|c|c|c|}
\hline & Sample & SP 1 & SP 2 & SP3 & SP 4 & SP 5 & SP 6 & SP 7 & SP 8 & SP 9 \\
\hline & Matrix & WPUA & $\begin{array}{l}\text { WPUA } \\
2317\end{array}$ & $\begin{array}{l}\text { WPUA } \\
2689\end{array}$ & WPUA & $\begin{array}{l}\text { WPUA } \\
2317\end{array}$ & $\begin{array}{l}\text { WPUA } \\
2689\end{array}$ & WPUA & $\begin{array}{l}\text { WPUA } \\
2317\end{array}$ & $\begin{array}{l}\text { WPUA } \\
2689\end{array}$ \\
\hline & $\begin{array}{l}\text { Glass fiber } \\
\mathrm{g} / \mathrm{m}^{2}\end{array}$ & 81 & 81 & 81 & 163 & 163 & 163 & 660 & 660 & 660 \\
\hline $\begin{array}{l}\text { Calculated } \\
\text { based on } \\
\text { thickness }\end{array}$ & $\begin{array}{l}\text { Fiber } \\
\text { Volume \% }\end{array}$ & 40 & 52 & 36 & 22 & 22 & 17 & 34 & 24 & 58 \\
\hline \multirow[t]{2}{*}{\begin{tabular}{l}
\multicolumn{2}{|l}{ Determined } \\
based on \\
weight \\
\end{tabular}} & $\begin{array}{l}\text { Fiber } \\
\text { Volume \% }\end{array}$ & 62 & 58 & 52 & 51 & 33 & 31 & 70 & 62 & 77 \\
\hline & $\begin{array}{l}\text { Matrix } \\
\text { Volume \% }\end{array}$ & 38 & 42 & 48 & 49 & 67 & 69 & 30 & 38 & 23 \\
\hline
\end{tabular}

Table 1. Fiber glass composite materials and their fiber volume

As can be seen from above mentioned results by the samples developed with glass fabric with weight $660 \mathrm{~g} / \mathrm{m}^{2}$ have a highest fiber volume content, because of the fiber size and different water content in the oligomers and its evaporation during the drying. That means that there is a change in matrix weight during drying. The distribution of the WPUA- into glass fabrics is supported by the water quantity which in comparison with epoxy and polyester matrix is an advantage because of the enhancement of the fiber volume content. 


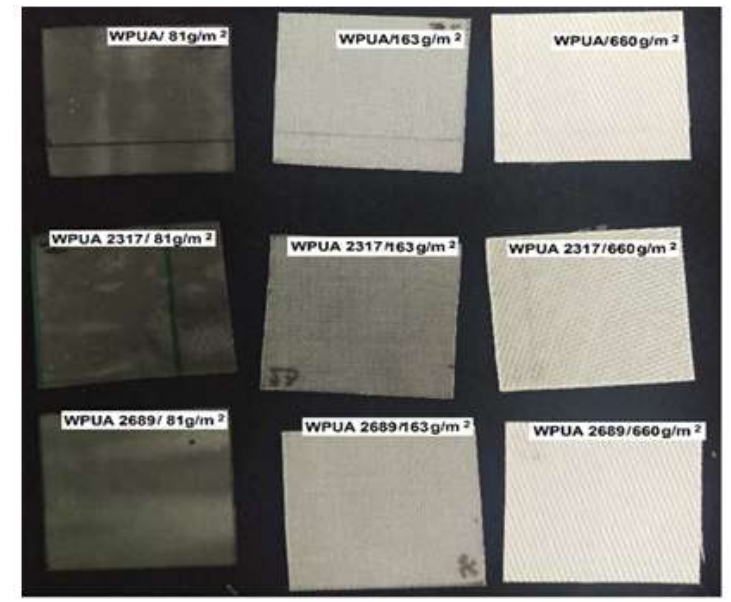

Pic.1. General overview of the obtained UV-cured composite materials

\section{Preparation of UV- cured fiberglass composites}

Fiberglass composites were prepared by applying of WPUA, WPUA 2317 and WPUA 2689 oligomers onto a Teflon plate covered by glass fabrics with weights of 81,163 and $660 \mathrm{~g} / \mathrm{m}^{2}$ and drying at $65^{\circ} \mathrm{C}$ for $3 \mathrm{~h}$. Because water was used as a diluent in this system, a flash-off step is needed, to remove the water by evaporation before UV-curing. During the water removal from the aqueous dispersion, entanglement occurred because of the large molecular weight of the prepolymer. Then the material was irradiated with the UV- light from a lamp (main wave length: $365 \mathrm{~nm}$, the power of the lamp: $400 \mathrm{~W}$, Spectral UV-A emission $1200 \mathrm{~mW} / \mathrm{m}^{2}$ and distance between the samples and the center of UV lamp of $15 \mathrm{~cm}$ ). The Irgacure 500 was activated and radicals for the polymerization were produced. The formed radicals react on the acrylate double bond of the monomers and due to radicalic polymerization polymers formed under crosslinking and finally the film is obtained. The UV-curable resins for the composites were prepared by mixing oligomer and photoinitiator at room temperature. The scheme of the overall process is shown in Fig. 1

Fig. 1: Process of fiberglass composites production

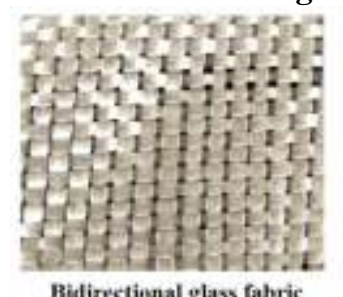

Bidirectional glass fabric

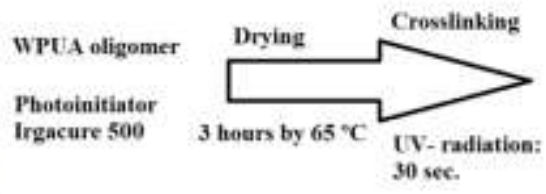

$$
30 \text { sec. }
$$

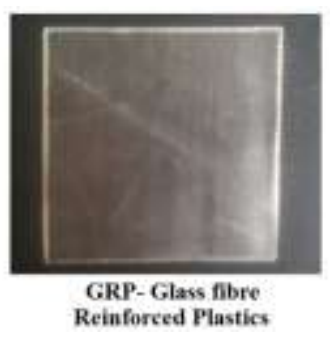

Reinforced Plastics

\section{Characterization techniques}

- Particle Size of the oligomers

For the determination of the particle size distribution of WPUA oligomers WPUA sample materials were filled to 5-ml test tubes and diluted with deionized water. The particle size was determined by light scattering with the laser particle size analyzer (Zetasizer Nano S Malvern Instruments Limited) according to ISO 13320:2009.

- Structure Characterization of the matrix (FT-IR).

ATR- FTIR (Attenuated Total Reflection) spectrum of the matrix was obtained according to ASTM E1252 - Standard Practice for General Techniques for Obtaining Infrared Spectra for Qualitative Analysis between 4000 and $400 \mathrm{~cm}^{-1}$ with an FT-IR spectrometer (Varian 620- IR, FT-IR). A minimum of 256 scans were measured and the results were averaged, with a resolution of $2 \mathrm{~cm}^{-1}$ in the $4000-400 \mathrm{~cm}^{-1}$ ranges.

- Mechanical Properties of UV-cured fiberglass composites

Tensile strength testing and elongation at break testing for all of the specimens were carried out on a tensile tester „Zwick Z 020" Zwick GmbH \& Co. KG, Ulm, Germany at room temperature at a speed of 10 $\mathrm{mm} / \mathrm{min}$. All determined parameters are averages of at least five measurements. The dumbbell-type specimens were prepared according to EN ISO 527-3:1995(ASTM D3039).

- Fiber Volume of the composites

Fiber volume ratio is easily determined by weighing of a defined area of the composites of known glass fiber grammage. The resin volume is determined as the difference between the volume of the composite and fiber volume and was calculated according to the following formula: 
$\mathrm{V}_{\mathrm{f}}+\mathrm{V}_{\mathrm{m}}=1$

$\mathrm{V}_{\mathrm{f}}-$ volume content of fibers, $\mathrm{V}_{\mathrm{m}}-$ volume content of matrix

$$
\mathrm{V}_{\mathrm{f}}=\frac{\mathrm{W}_{\mathrm{f}} / \rho_{\mathrm{f}}}{\mathrm{W}_{\mathrm{f}} / \rho_{\mathrm{f}}+\left(\mathrm{W}_{\mathrm{c}}-\mathrm{W}_{\mathrm{f}}\right) / \rho_{\mathrm{m}}}
$$

$\mathrm{W}_{\mathrm{c}}=\mathrm{W}_{\mathrm{f}}+\mathrm{W}_{\mathrm{m}}$

$\mathrm{W}_{\mathrm{c}}$ - weight of the composite, $\mathrm{W}_{\mathrm{f}}$ - weight of the fiber, $\mathrm{W}_{\mathrm{m}}$ - weight of the matrix

$\rho_{\mathrm{f}}$ - density of the fiber, $\rho_{\mathrm{m}}$ - density of the matrix

- Thermal properties of fiberglass

Differential scanning calorimetry (DSC) of the UV-cured fiberglass composites were performed at a „DSC 204 Phoenix", NETZSCH, Germany according to ISO 11357. The programmed heating range was from $100^{\circ} \mathrm{C}$ to $300^{\circ} \mathrm{C}$ at a heating rate of $10 \mathrm{~K} / \mathrm{min}$ under a nitrogen atmosphere. The measurement was performed at 6-10 mg samples and DSC curves were recorded.

\section{- Focused ion beam Microscope analysis}

The samples for microscopy were prepared by sputter coating with $50 \mathrm{~nm}$ thick gold layer at pressure, $\mathrm{p}$ of $10^{-2}$ bar and a current I of $50 \mathrm{~mA}$. The machine used during this process was a high vacuum sputter coater (LEICA EM SCD 500, Germany). The fiber surface morphology was investigated using a Focused ion beam Microscope model Micron 9100, Germany.

\section{Particle Size of oligomers}

\section{Results And Discussions}

Figure 2 presents the results obtained for particle sizes of the investigated aqueous dispersion. For WPUA the average size is about 145,0 nm in comparison with WPUA 2317 at about 88,4 nm and 101,7 nm for WPUA 2689. WPUA dispersion is stabilized due to the formation of electric double layers between polar constituents which are present in the polyurethane network. The interference of electric double layers of different particles leads to a stabilization mechanism of the dispersion. Colloidal stabilization is mainly because of electrostatic and steric stabilization or a combination of both. From the particle size results was concluded that the ionic center content is inversely proportional to the particle size. It is a well-known phenomenon that particle size has a direct effect on dispersion stability, thus larger sized particles get sedimented easily and as a result the dispersion loses its stability [15]. The data also show that the particle size distribution curves have a single peak confirming the copolymerization between PU and acrylate components in WPUA composite. The properties of the synthesized WPUA have been described in our previous study [14].
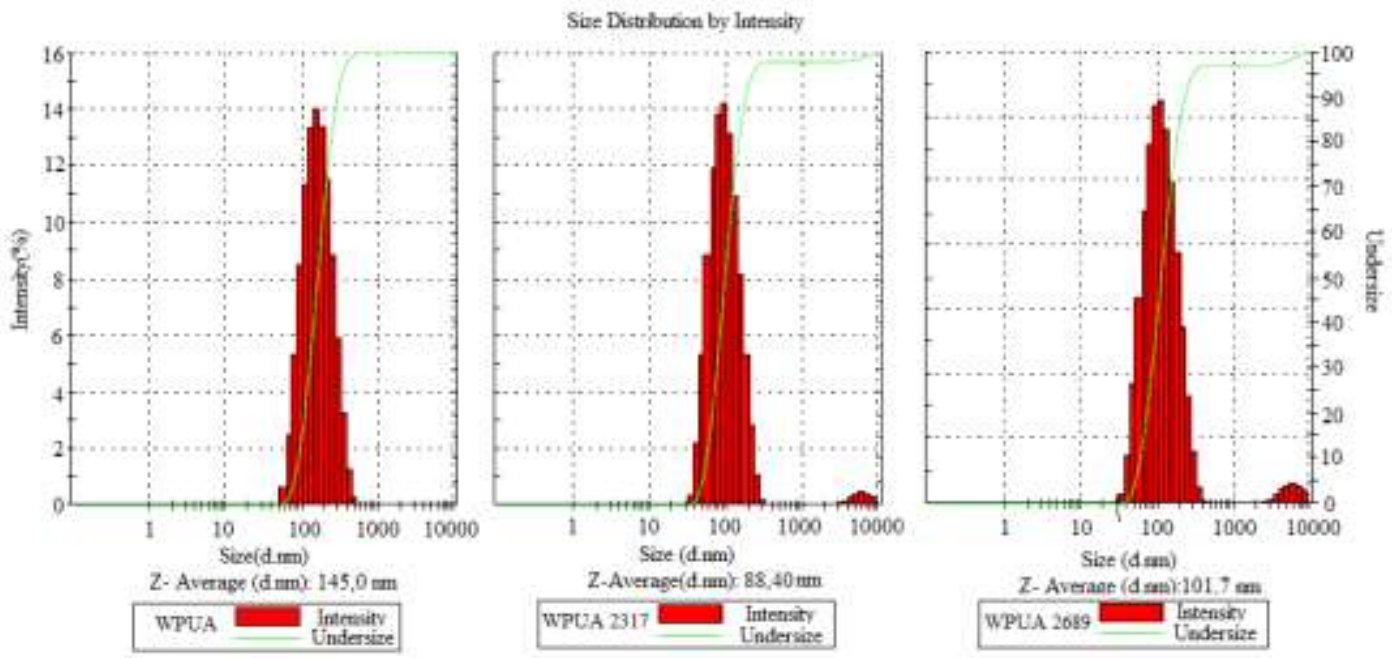

Fig. 2 Particle size distribution of oligomers

It is expected, that this strong relation between particle sizes of oligomers is going to affect the physical properties of the dispersions. 


\section{ATR Spectra Of The Matrix}

The ATR-FTIR analysis presented in Figures 3, 3.1 and 3.2 had been used mainly to investigate the completeness of the UV- polymerization reaction. The presence of a band at $1538,1531 \mathrm{~cm}^{-1}$ belongs to C-NH group from the urethane. The strong bands at 2980- $2865 \mathrm{~cm}^{-1}$ are aliphatic C-H stretching asymmetric and symmetric vibration, as well as asymmetric and symmetric stretching $\mathrm{CH}_{3}$. There are wide peaks at 3379,3372 , $3369 \mathrm{~cm}^{-1}$, which belongs to the $\mathrm{OH}$ groups and the peaks at $1150-1000 \mathrm{~cm}^{-1}$ belongs to the (C-O) bond. As can be observed by the samples WPUA 2317 and WPUA 2689 reducing the intensity of the bands at $1634 \mathrm{~cm}^{-1}$, $1407 \mathrm{~cm}^{-1}$ and $809 \mathrm{~cm}^{-1}$ and for WPUA sample displacement of the band at $837 \mathrm{~cm}^{-1}$ give reason to conclude that there is existence of destruction of the double vinyl bonds and UV-hardening has proceeded. The shift of the peaks after UV-curing was as a result of polymerization, whereas the double bond $\left(\mathrm{CH}_{2}=\mathrm{CH}-\right)$ in the acrylate moiety reacts. These vibrations are considered as strong evidence for the formation of polymer network.

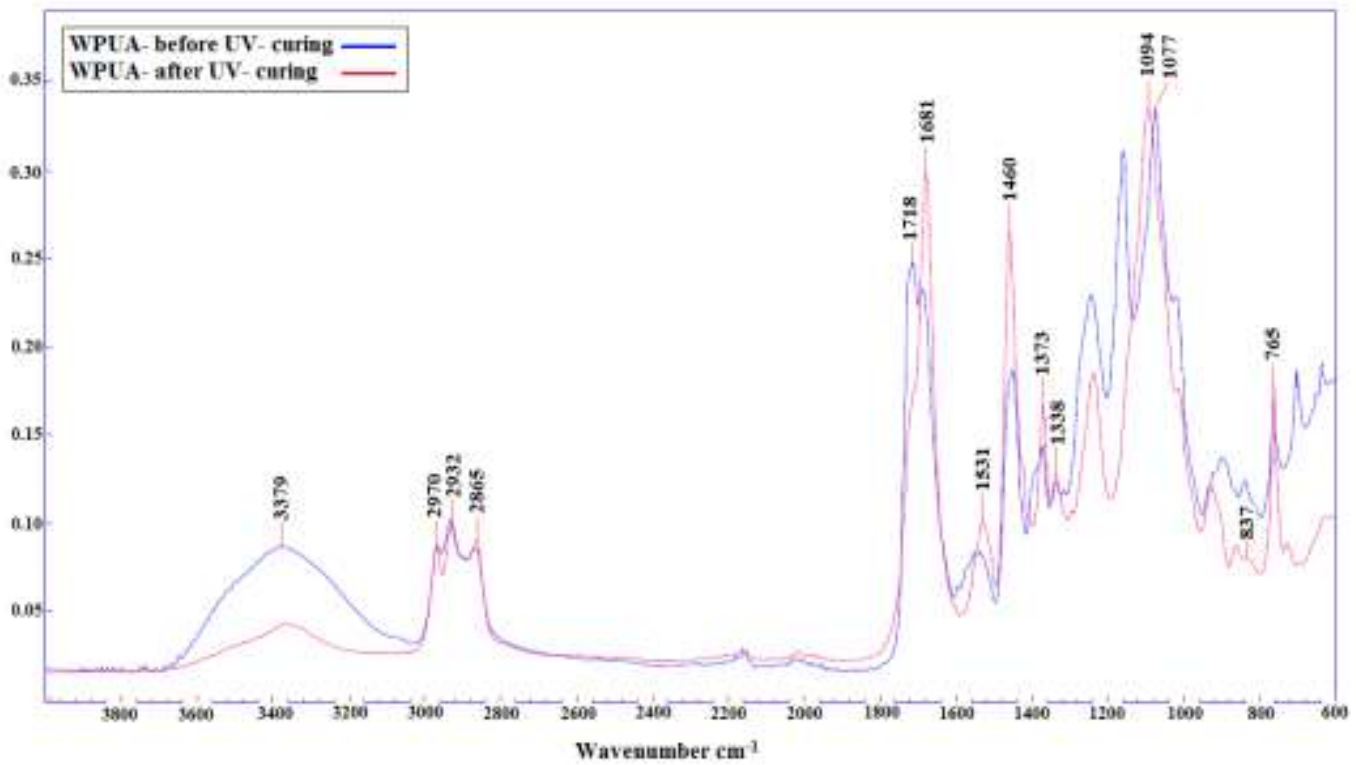

Fig. 3. FTIR analysis of the used WPUA

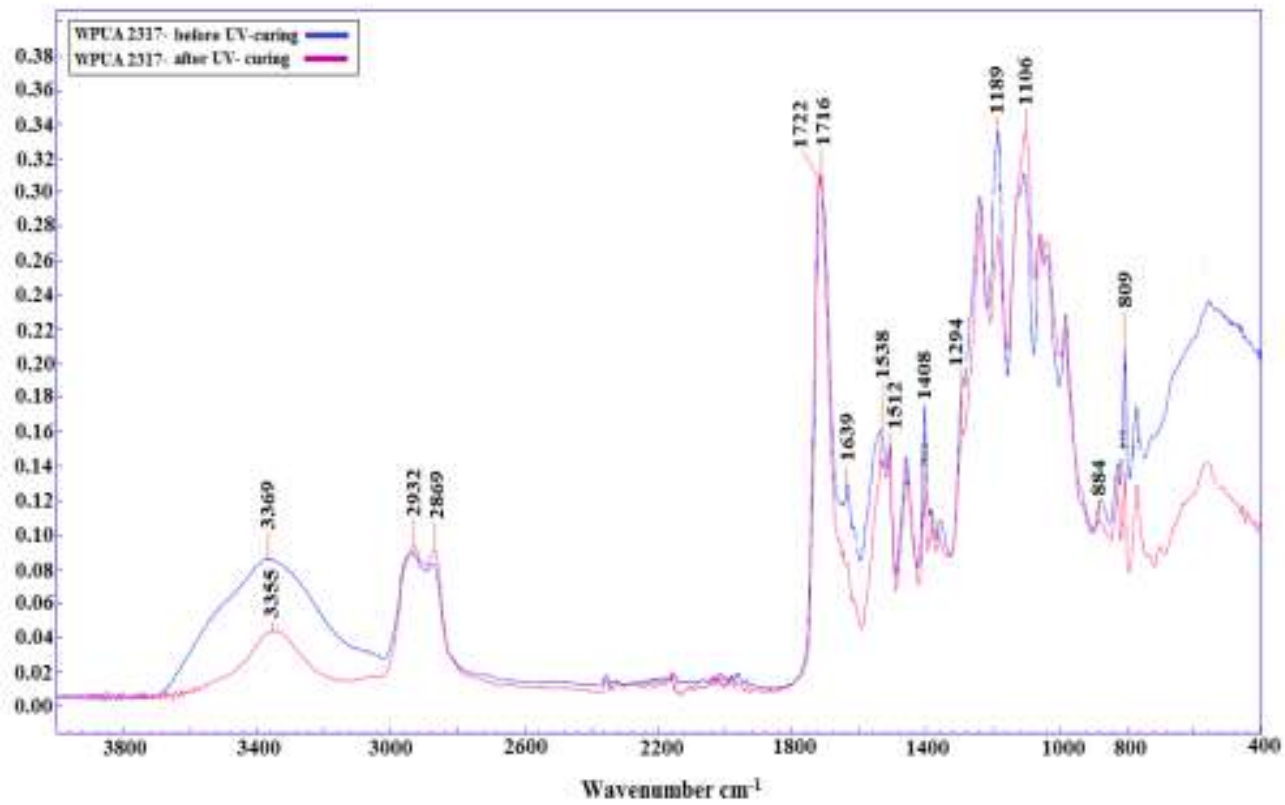

Fig. 3.1. FTIR analysis of the used WPUA 2317 


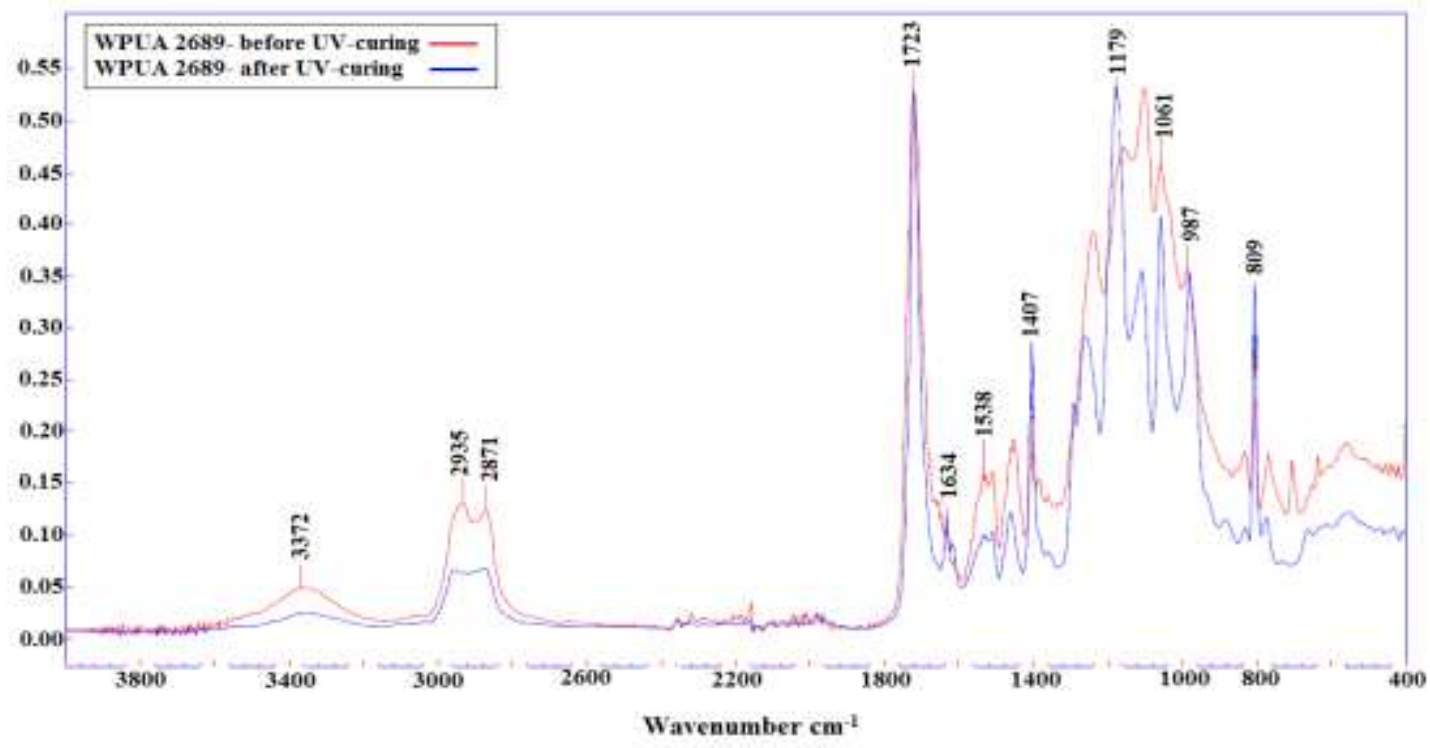

Fig. 3.2. FTIR analysis of the used WPUA 2689

\section{Differential Scanning Calorimetry of the Composite Materials}

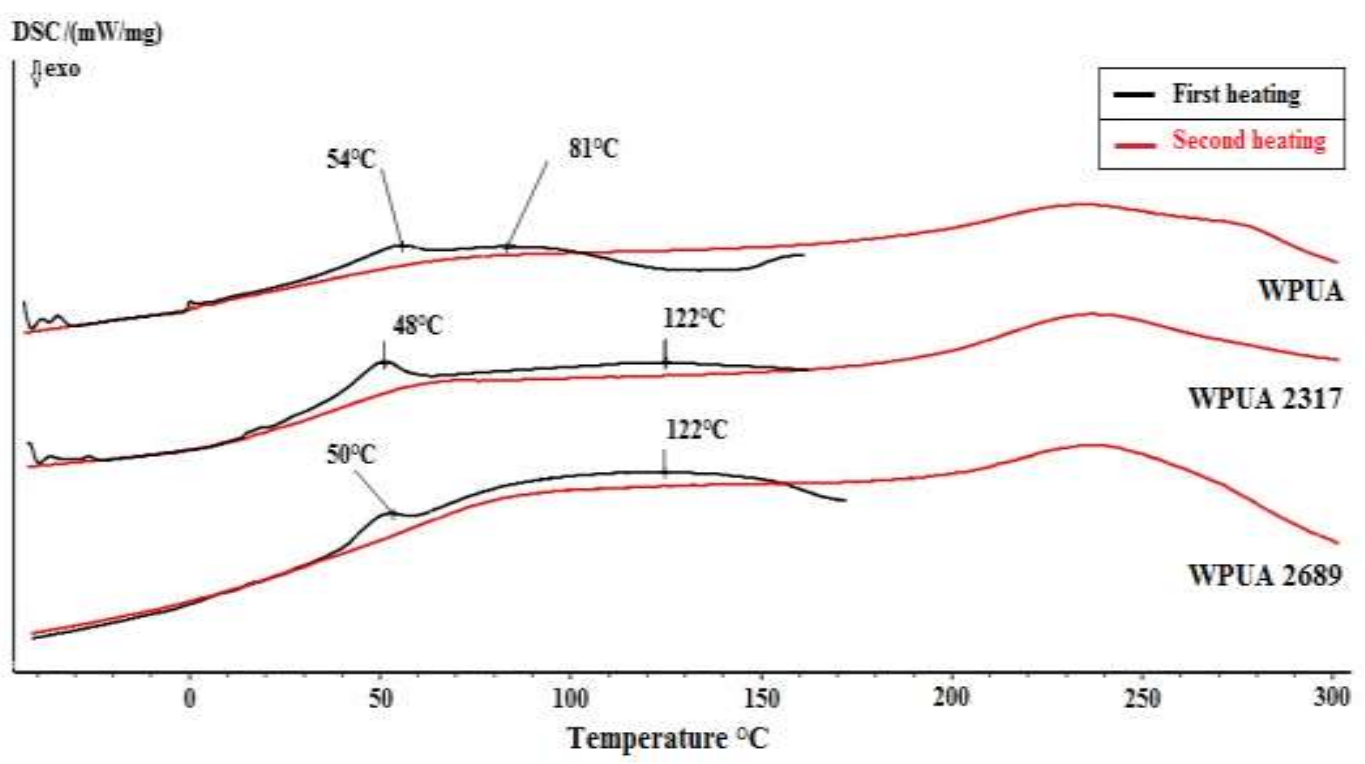

Fig. 4. DSC of the different WPUA fiberglass composites

The DSC curves of the fiberglass composites are shown in Figure 4. They are the result of a heat-up in a first run to $160{ }^{\circ} \mathrm{C}$ and the second run to $300^{\circ} \mathrm{C}$. The first heating is to remove residues of the bound water in the material (if any). In the first heating are observed two peaks for WPUA at $54{ }^{\circ} \mathrm{C}$ and $48{ }^{\circ} \mathrm{C}$ for WPUA 2317 that best - probably due to the residues of the photo-initiator which recrystallized and peak at $81{ }^{\circ} \mathrm{C}$ for WPUA matrices and an endothermic peak at $122{ }^{\circ} \mathrm{C}$ at WPUA 2317 matrix which best - probably related to the separation of water. The endothermic peak between $200{ }^{\circ} \mathrm{C}$ and $250{ }^{\circ} \mathrm{C}$ speaks melting microcrystalline hard segment of polyurethane $[17,18]$. The thermal properties of the material obtained from WPUA 2689, do not differ from those obtained with WPUA 2317. The N-H group in polyurethane could form hard segment $\mathrm{H}-$ bonding with the carbonyl oxygen and soft $\mathrm{H}$-bonding with the ether oxygen. The stronger hard segment acts as physical crosslinks, leading to a difficult segmental motion of the polymer chain, which results in a more significant phase separation between the hard and soft segments. The phase separation improves mechanical properties of polyurethanes but reduces their flexibility and solubility [16]. 


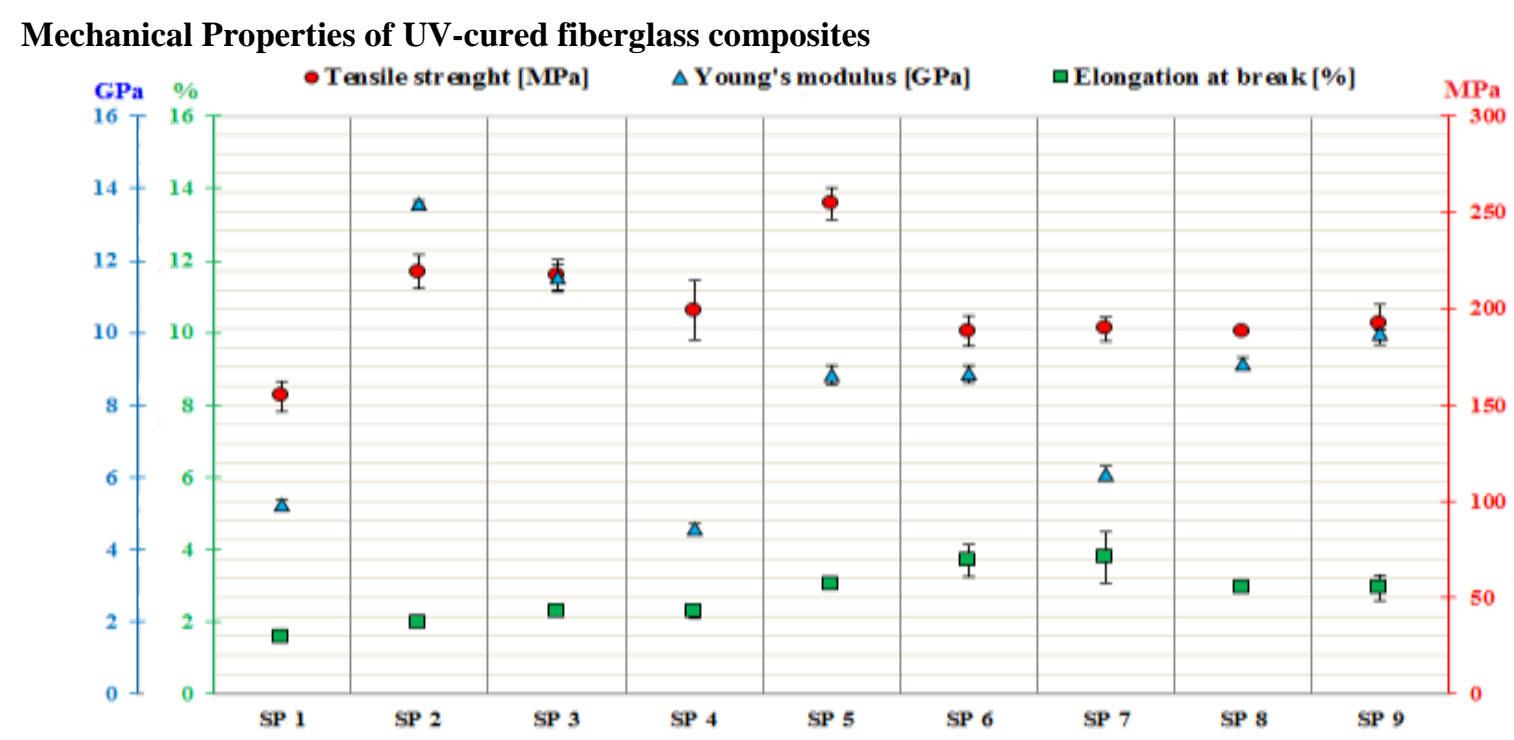

Fig. 5. Tensile strength, flexure modulus and elongation at break of the glass fiber reinforced WPUA composites.

Figure 5 presents the results for the mechanical properties of the prepared composite materials with WPUA matrices and different glass fiber contents. The best results for tensile strength were received with glass fibers composite material with a weight of the glass fiber fabric of $163 \mathrm{~g} / \mathrm{m}^{2}$ and WPUA 2317 and with a value $254,71 \mathrm{MPa}$. The usage of fiber-glass material with higher density, thicker structure and higher weight than 163 $\mathrm{g} / \mathrm{m}^{2}$ led to aggravation of the tensile strength. This most probably was due to the insufficient quantity of the polymer matrix during the production process and after the drying process of the composite material the result is consequent incomplete adhesion between the matrix and the glass fibers.

The tensile strength of the obtained composite materials prepared with WPUA 2317 and WPUA 2689 as polymer matrices and glass fiber fabric of $81 \mathrm{~g} / \mathrm{m}^{2}$ have a values of about $220 \mathrm{MPa}$. Optimal elongation at break value at 3,7 \% was obtained by the sample prepared with oligomer WPUA 2689 and glass fabric with a weight of $163 \mathrm{~g} / \mathrm{m}^{2}$ which is almost double distinction compared with the sample obtained from WPUA and glass fabric with mass $163 \mathrm{~g} / \mathrm{m}^{2}$.

As can be seen the composites obtained with the synthesized WPUA have the lowest Young's modulus, which is due to the lowest stiffness and high elasticity of the polymer matrix. The highest elasticity modulus at about $13 \mathrm{GPa}$ is obtained for the composites which consist of glass fibers $81 \mathrm{~g} / \mathrm{m}^{2}$ and WPUA 2317 . The mechanical characteristics of a glass fiber reinforced composite depend not only on the properties of the fiber, but also on the fiber orientation and on the fiber volume concentration in the matrix. The arrangement or orientation of the fibers relative to one another, the fiber concentration, and the distribution all have a significant influence on the strength and other properties of the composites. With respect to orientation, two extremes are possible: (1) a parallel alignment of the longitudinal axis of the fibers in a single direction, and (2) a totally random alignment.

\section{Matrix distribution}

Figure 6 shows the glassfiber reinforced laminates with uniformly distributed polymer matrix and with the unevenly distributed matrix, incompletely filling the thickness of the sample. There is a volume and quantity difference in each different matrix used for obtaining glass fiber reinforced composite, which is related to the evaporated water.

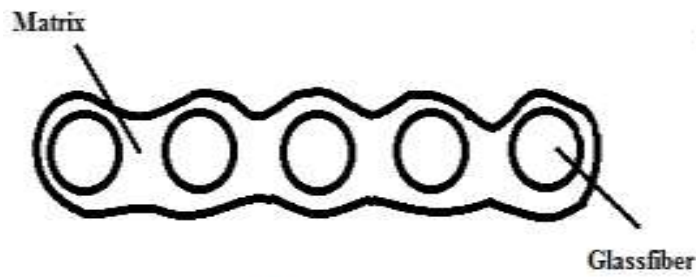

Unevenly distributed matrix

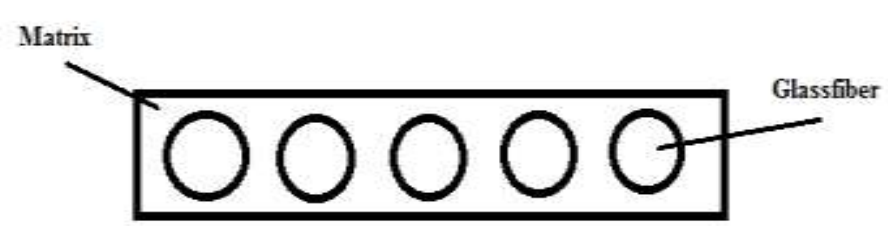

Uniformly distributed matrix

Fig.6. Cross- section of the glass fiber reinforced composites 


\section{Calculated And Determined Properties Of The Composites}

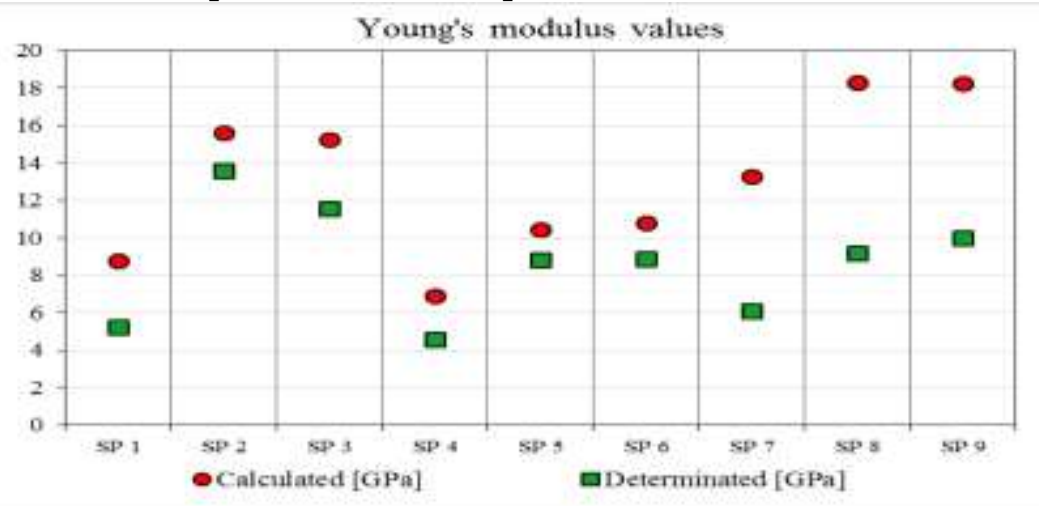

Fig.7. Calculated and determinated Young's modulus values of the composites according to matrix distribution

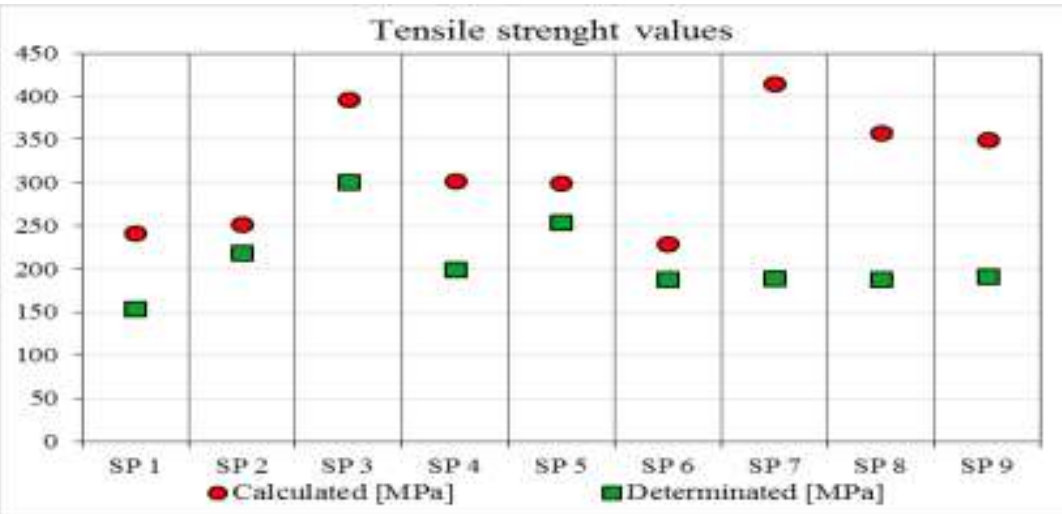

Fig. 7.1. Calculated and determinated tensile strength values of the composites according to matrix distribution

At Figures 7 and 7.1 can be seen the determined (by determination of the thickness by a digital measuring slide) and calculated (by use of aforementioned formula and weighted grammage) values of Young's modulus and tensile strenght, whose contrast could be explained by the uneven distribution and a lower amount of matrix in the prepared composites. It can be observed that by the composite obtained with WPUA polyols the matrix distribution is uneven because of evaporated water quantity after drying process, wich explain the difference between calculated and determined properties of the composites shown in figure 7, 7.1 and table 1.

\section{Focused ion beam Microscopy}

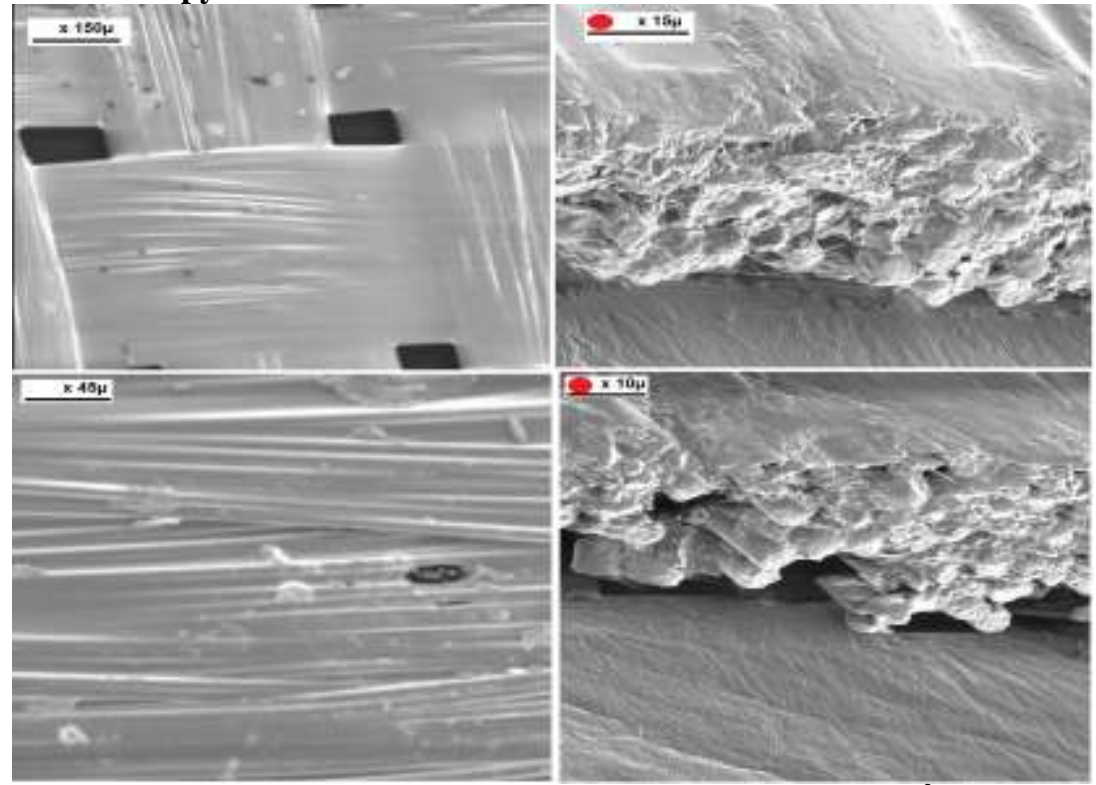

Fig. 8. Microscope image of composite obtained with glass fabric $81 \mathrm{~g} / \mathrm{m}^{2}$ and WPUA matrix 
From microscopic examination made could be concluded that the glass fibers in the various bundles are bound together by the polymer matrix. That is sign for good adhesion between the glass fibers and the matrix. The images showing the breaking edge of the composite (marked with a red dot) did not indicate a clear phase boundary between the matrix and the fibers, but friction prevents from fiber pull out at the edge.

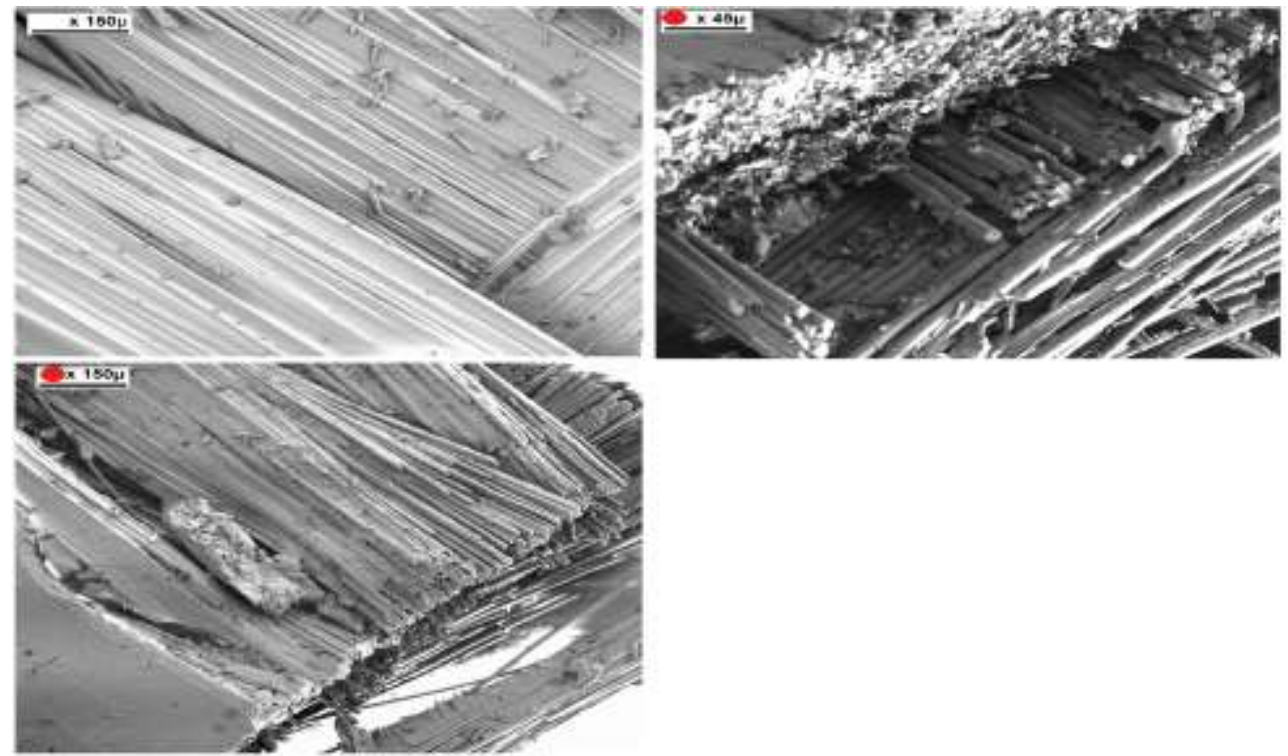

Fig. 9. Microscope image of composite obtained with glass fabric $660 \mathrm{~g} / \mathrm{m}^{2}$ and WPUA matrix

Microscopic examination of the composites prepared with glass fabric $660 \mathrm{~g} / \mathrm{m}^{2}$ revealed that the matrix surface and the fibers are not securely connected because the surface of the fibers are incompletely connected to the matrix, which is shown on the pictures of the composite material marked with red dots. The microscopy of the section indicate that the glass fibers which are in the "depth" in the composite are not crosslinked and connected by a matrix, which leads to the following conclusion: If the grammage of the glass fabric is higher and the amount of resin in the dispersion is not sufficient, the low viscosity of the system is not sufficient for a continuous impregnation and the use of a larger quantity of resin or layered production of composite materials is necessary.

\section{Conclusions}

From above discussed results it could be concluded that the process for preparation of UV-cured composites improve the content of reinforcing material and therefore the mechanical properties. The additional time for drying is compensated by UV- curing. An increase in the quantity of the matrix could prevent an unevenly distribution and lead better composite surface properties. There are many types of photoinitiators and UV-sources which can be used in the composite preparing process.

Concluding from the presented results, there is a suitable glass fiber weight of the WPUA 2371 composite material of about $81-163 \mathrm{~g} / \mathrm{m}^{2}$, which shows most improved strength properties. Above this grammage the matrix volume is not enough and the UV-curing process not pass through entire area of the composite material, because of the UV- transparency of the glass. The obtained experimental results provide the possibility of using such kind of composite materials to carry out repairs by UV-curing fiberglass water-borne polyurethane acrylate systems because of its fast UV-curing and the possibility of finishing the curing process by the UV-daylight. Furthermore, additional experiments could be carried out with more than one layer of fiber glass material, depending on the applied conditions and purposes.

\section{References}

[1]. William Jr D Callister and David G Rethwisch, Materials Science and Engineering: An Introduction. Ninth Edition (John Wiley \& Sons, 2013).

[2]. Michael Szycher Ph.D, Szycher's Handbook of Polyurethanes, Second Edition (CRC Press 2013)

[3]. Ho Tak Jeon et al., Synthesis and characterizations of waterborne polyurethane- silica hybrids using sol- gel process, Colloids and Surfaces A: Physicochem. Eng. Apects 302, 2007, 559-567.

[4]. Hemul V. Patel et al., Preparation and performance of UV curable polyurethane coating for metal surfaces, Archives of Applied Science Research, 1 (2), 2009, 294- 305

[5]. Minqiang He et al., Preparation, Characterization, and Property Analysis of Environmentally Friendly Waterborne PolyurethaneAcrylate, International Journal of Polymer Anal. Charact, 18, 2013, 211- 223

[6]. Heping $\mathrm{Xu}$ et al., UV-curable waterborne polyurethane- acrylate: preparation, characterization and properties, Progress in Organic Coatings 73, 2012, 47-53 
[7]. Christian Decker, Kinetic Study and New Applications of UV Radiation Curing, Macromol. Rapid Commun, 23, 2002,1067 - 1093

[8]. Atul Tiwari et al., Photocured Materials, (Royal Society of Chemistry, 2014)

[9]. L. Keller et al. Synthesis of polymer nano- composites by UV- curing of organoclay- acrylic resins, Polymer 45, 2004, 7437- 7447

[10]. Ghodsieh Mashouf et al., UV curable urethane acrylate coatings formulation: experimental design approach, Pigment \& Resin Technology, Vol. 43 Iss 2 pp., 2014, 61 - 68

[11]. Caroline Sow, Bernard Riedl, Pierre Blanchet, Kinetic studies of UV- waterborne nanocomposite formulations with nanoalumina and nanosilica, Progress in Organic Coatings $67,2010,188-194$

[12]. K. M. Idriss All, Mubarak A. Khan, M. M. Zaman, M. A. Hossain, Reactive diluent effect on properties of UV- cured films, Journal of Applied Polymer Science (Impact Factor: 1.64), 54(3), 10/1994, 309 - 315

[13]. Nicholas P. Cheremisinoff, Fiberglass Reinforced Plastics, 1st Edition,( Elsevier 1995), 24

[14]. Andrey Matev, Petar Velev, Selen Ismail, Michael Herzog, Preparing, properties and application of waterborne polyurethaneacrylate oligomer as a matrix in UV-cured fiberglasses, Ninth National Conference on Chemistry, Sofia (2016)

[15]. Gururaj N. Manvi and Ramanand N. Jagtap, Effect of DMPA Content of Polyurethane Dispersion on Coating Properties Journal of Dispersion Science and Technology 31, 2010, 1376-1382

[16]. M. Barikani, M. Valipour Ebrahimi, S. M. Seyed Mohaghegh, Preparation and Characterization of Aqueous Polyurethane Dispersions Containing Ionic Centers, Journal of Applied Polymer Science, Vol. 104, 2007, 3931-3937

[17]. R. W. Seymour and S. L. Cooper, "Thermal analysis of polyurethane block polymers," Macromolecules, vol. 6, no. 1, pp. 48-53, Jan. 1973.

[18]. T.-L. Lin, T. L. Yu, W.-J. Liu, and Y.-M. Tsai, "Phase segregation of Crosslinked polyurethane by small angle x-ray scattering," Polymer Journal, vol. 31, no. 2, pp. 120-126, Feb. 1999. 